Harrison, B. D. (1956). J. gen. Microbiol. 15, 210-220

\title{
The Infectivity of Extracts made from Leaves at Intervals after Inoculation with Viruses
}

\author{
BY B. D. HARRISON* \\ Rothamsted Experimental Station, Harpenden, Hertfordshire
}

SUMMARY: When leaves are macerated at intervals after being inoculated with plant viruses, the infectivity of the extracts obtained decreases with increasing time until newly produced virus becomes detectable. Infectivity does not start to increase until approximately twice the time apparently needed for virus to multiply in the epidermis and spread from there to the mesophyll. Epidermal cells infected by inoculation seem to produce too few virus particles to be detected by infectivity tests or else the first-formed particles are unstable in vitro.

No evidence was obtained, with Rothamsted tobacco necrosis virus (RTNV) in leaves of tobacco and French bean, that the initial decrease in infectivity occurs because of changes in virus particles that succeed in infecting and causing lesions. If such changes occur they are obscured by the inactivation of particles that do not multiply and cause lesions. Washing inoculated leaves removes $95 \%$ of the inoculated virus, but only slightly decreases the numbers of infections, and adding 'Celite' to the inoculum greatly increases the numbers of lesions without increasing the amount of virus retained by washed leaves. Neither washing nor adding 'Celite' to the inoculum affects the rate at which the infectivity of successive extracts from inoculated leaves decreases. Infectivity continues to decrease after virus appears to have multiplied in and spread from the epidermis.

Cells of Nicotiana glutinosa that are infected by tobacco mosaic virus spreading from inoculated epidermal cells die only a few hours after the infectivity of leaf extracts starts to increase: few cells seem to become infected from virus produced in these secondarily infected cells and, at $2^{\circ}$, infectivity reaches a maximum in 2 days. Mesophyll cells of French bean leaves at $22^{\circ}$ seem to synthesize new RTNV particles within $5 \mathrm{hr}$. of becoming infected from the epidermis and to continue synthesizing for another $30 \mathrm{hr}$., when they probably contain about $10^{6}$ virus particles/cell. Although the cells then die, the virus spreads to further cells and the infectivity of leaf extracts increases for at least five days.

Although Holmes first investigated the infectivity of extracts of tobacco leaves made at intervals after inoculation with tobacco mosaic virus in 1930 , only recently have any detailed results been obtained for the hours immediately following inoculation (Bawden \& Pirie, 1953; Yarwood, 1952; White, 1954). These results showed that the infectivity of successive extracts of tobacco or Datura stramonium leaves usually decreased for some hours after inoculation with tobacco mosaic virus. By contrast, when assays were made on extracts by counting the number of virus particles visible in the electron microscope, no such decrease was detected (Steere, 1952). The experiments described in this paper were made to see whether the initial decrease in infectivity occurs at all generally, and to compare the time needed for infectivity of leaf extracts to increase with that found for other changes which have been detected in inoculated leaves (Bawden \& Harrison, 1955).

* Present address: Scottish Horticultural Research Institute, Invergowrie, by Dundee. 


\section{METHODS}

The viruses used were Rothamsted tobacco necrosis virus (RTNV), and two strains of tobacco mosaic, the type strain and tomato aucuba mosaic virus. Inoculum of RTNV was infective sap which had been stored frozen; purified preparations of tobacco mosaic and tomato aucuba mosaic viruses were used. The viruses were diluted in distilled water. When 'Celite' (Johns-Manville) was used to increase the number of local lesions, it was mixed in the inoculum. The two primary leaves of French bean plants (Phaseolus vulgaris L. var. Prince) were used when almost fully expanded, and the apical shoot was removed. Tobacco plants (Nicotiana tabacum L. var. White Burley) were used when they had three leaves of $12-25 \mathrm{~cm}$. in length and $N$. glutinosa $\mathbf{L}$. plants with six leaves of $6-12 \mathrm{~cm}$. in length. The plants were grown in a glasshouse with a mean temperature of $20^{\circ}$.

Inoculations were made by rubbing the upper surface of leaves with the forefinger wet with inoculum. Leaf extracts, made from disks punched out of the leaf blades (Harrison, 1956), were stored frozen, and were thawed and clarified by centrifuging at 10000 r.p.m. for infectivity assays. Infectivity was assayed by comparing the number of local lesions produced by different inocula on a batch of test plants. The treatments were distributed so that each occurred equally on right- and left-hand halves of leaves and at each leaf position. At least six half-leaves were used for each treatment.

Ultraviolet radiation was provided by a low-pressure mercury-discharge lamp (Thermal Syndicate Ltd.); most of the radiation was of $2537 \AA$. and at $20 \mathrm{~cm}$. from the lamp, the distance used, the radiation intensity was $870 \mu \mathrm{W}$./ cm. ${ }^{2}$.

\section{RESULTS}

\section{The first detectable virus increase}

To find the shortest time in which newly formed virus became detectable in French bean leaves inoculated with RTNV, infective sap diluted $1 / 2$ and containing 'Celite' was used as the inoculum: the leaves were thoroughly washed after inoculation. About 600 lesions/half-leaf were produced, the maximum number possible. The temperature was about $22^{\circ}$, the optimum for accumulation of RTNV in French bean leaves (Harrison, 1956). Preliminary experiments showed that the infectivity of extracts from such leaves decreased for $6 \mathrm{hr}$; in the experiments whose results are given in Table 1, the leaves were not sampled until $3 \mathrm{hr}$. after they were inoculated. The infectivity of extracts did not increase until between 9 and $10.5 \mathrm{hr}$. after inoculation; approximately twice the time that the virus seems to need to penetrate into the mesophyll and to be protected from inactivation by ultraviolet radiation (Bawden \& Harrison, 1955). If, as seems probable, the time to reach the mesophyll is occupied by virus from the inoculum multiplying in the epidermis, the first lot of virus produced in the epidermis is not detected in leaf extracts, possibly because there is too little of it. The first increase in infectivity may represent the beginning of virus formation in these secondarily infected cells, of which 
there will probably be many more than the epidermal cells infected by inoculation. However, another possibility is that the virus as first formed spreads to new cells in the leaf but is unstable in vitro, and that forms which are stable in extracts do not occur until later. At $\mathbf{2 2}^{\circ}$, lesions appear in about $40 \mathrm{hr}$. after inoculation, and the mesophyll cells which die then can only have been infected for $35 \mathrm{hr}$. at the most. Assuming $5 \mathrm{hr}$. also is needed for the first virus to be formed in these cells, there is a period of $30 \mathrm{hr}$. during which RTNV accumulates inside them.

\section{Table 1. The first detectable increase of tobacco necrosis virus in French bean leaves}

Inoculum was infective French bean sap diluted $1 / 2$ and containing 'Celite'. Total lesions produced on sixteen half-leaves of French bean by sample diluted 1/25 and containing 'Celite' were counted.

\begin{tabular}{|c|c|c|c|c|c|c|c|}
\hline & \multicolumn{6}{|c|}{ Time after inoculation (hr.) } & \multirow{3}{*}{$\begin{array}{c}\text { Average } \\
\text { temp. } \\
\left({ }^{\circ} \mathrm{C} .\right)\end{array}$} \\
\hline & $\mathbf{3}$ & 6 & $7 \cdot 5$ & $\mathbf{9}$ & $10 \cdot 5$ & 12 & \\
\hline & \multicolumn{6}{|c|}{ Total lesions produced } & \\
\hline $\mathbf{A}$ & 378 & 264 & 356 & 382 & $\mathbf{5 3 5}$ & $\mathbf{8 4 0}$ & 25 \\
\hline $\mathbf{B}$ & 329 & 214 & 218 & 295 & 539 & 1461 & 21 \\
\hline \multirow[t]{2}{*}{$\mathbf{C}$} & 435 & 309 & 329 & 267 & 634 & 814 & 23 \\
\hline & 1142 & 787 & 903 & 944 & 1708 & 3115 & \\
\hline
\end{tabular}

Table 2. The virus content of leaves and effect of irradiation at different times after inoculation

Host plant: Nicotiana glutinosa. Inocula: $100 \mathrm{mg}$. virus/l.; no 'Celite'. Total lesions produced on twenty-four half-leaves of Nicotiana glutinosa by samples diluted $1 / 5$ and containing 'Celite' were counted.

\begin{tabular}{|c|c|c|c|c|}
\hline \multirow[b]{2}{*}{$\begin{array}{c}\text { Time after } \\
\text { inoculation } \\
\text { (hr.) }\end{array}$} & \multicolumn{2}{|c|}{ Tomato aucuba mosaic virus } & \multicolumn{2}{|c|}{ Tobacco mosaic virus } \\
\hline & $\begin{array}{c}\text { Infectivity of } \\
\text { leaf extract } \\
\text { (no. lesions) }\end{array}$ & $\begin{array}{c}\text { Lesions } \\
\text { developing on } \\
\text { irradiated leaves } \\
\text { as percentage } \\
\text { of control }\end{array}$ & $\begin{array}{l}\text { Infectivity of } \\
\text { leaf extract } \\
\text { (no. lesions) }\end{array}$ & $\begin{array}{c}\text { Lesions } \\
\text { developing on } \\
\text { irradiated leaves } \\
\text { as percentage } \\
\text { of control }\end{array}$ \\
\hline 1 & 84 & 1.5 & 232 & $\mathbf{2} \cdot \mathbf{6}$ \\
\hline 16.5 & 60 & - & 118 & - \\
\hline $\mathbf{2 0}$ & - & $50 \cdot 5$ & - & $61 \cdot 6$ \\
\hline 25 & 60 & - & 28 & - \\
\hline $40 \cdot 5$ & 59 & 一 & 133 & - \\
\hline 44 & - & $97 \cdot 0 *$ & - & $107 \cdot 0 *$ \\
\hline 49 & 929 & - & 1413 & - \\
\hline 64 & 904 & 一 & 885 & - - \\
\hline
\end{tabular}

In Nicotiana glutinosa leaves inoculated with tobacco mosaic or tomato aucuba mosaic viruses, the time taken for newly produced virus to become detectable in extracts was twice that apparently needed for virus to move from the inoculated epidermis into the mesophyll. Table 2 shows that, with both viruses, the first substantial increase in infectivity occurred between 
40.5 and $49 \mathrm{hr}$. About half the control number of lesions developed on leaves that were irradiated for $3 \mathrm{~min}$. with ultraviolet radiation at $20 \mathrm{hr}$. after inoculation, and this is taken to be the average time needed for these viruses to multiply in and move from the epidermis into the mesophyll (Bawden \& Harrison, 1955). This time is longer than that found by Bawden \& Harrison, probably because the experiment was made at a lower temperature; the time taken by RTNV to become insusceptible to ultraviolet radiation in French

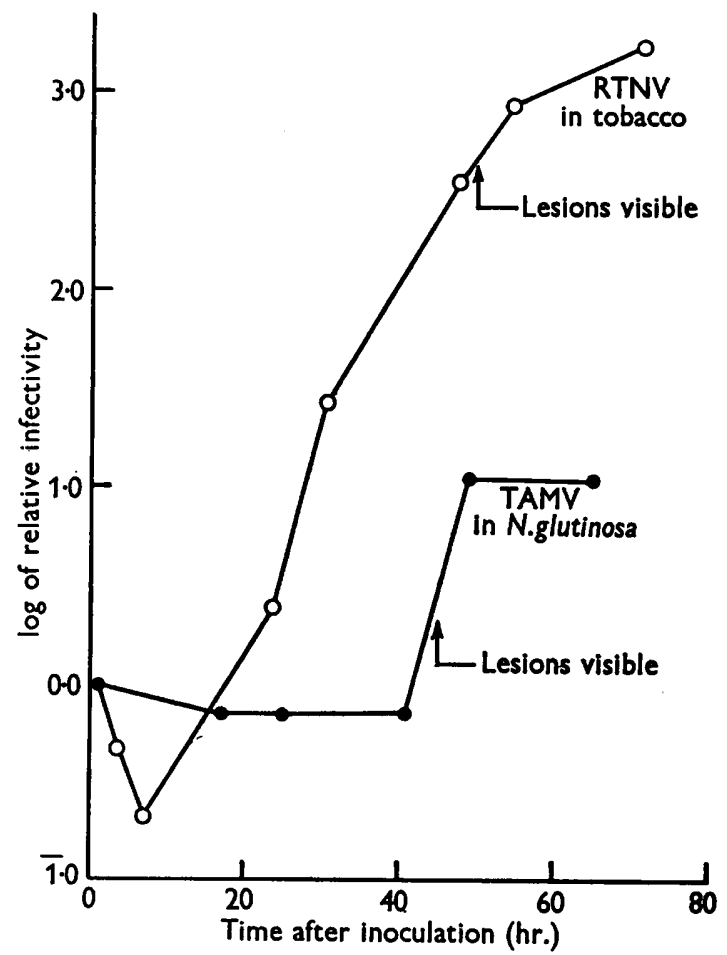

Fig. 1. Increase of tobacco necrosis (RTNV) and tomato aucuba mosaic (TAMV) viruses in inoculated leaves. Leaves washed after inoculation. The inocula were: RTNV, infective tobacco sap diluted 1/4, with 'Celite' added; TAMV, $100 \mathrm{mg} \cdot / 1 .$, no 'Celite'. RTNV was assayed by inoculating French bean, and TAMV in Nicotiana glutinosa.

bean leaves varies greatly with change of temperature (Harrison, 1956), and other viruses might be expected to behave similarly. Both tobacco mosaic and tomato aucuba mosaic viruses caused necrotic lesions to appear $45 \mathrm{hr}$. after inoculation, only a few hours after the infectivity of the leaf extracts had increased detectably. At about $20^{\circ}$, mesophyll cells of $N$. glutinosa leaves seem to synthesize these viruses within $20 \mathrm{hr}$. of becoming infected and to die when synthesis has gone on for a further 5-10 hr. These processes are accelerated by increasing the temperature, and tomato aucuba mosaic virus multiplies detectably in $21 \mathrm{hr}$. at $27^{\circ}$ and $30^{\circ}$ (Harrison, 1956).

Fig. I shows that the infectivity of successive extracts from leaves inoculated with RTNV, once it had started to increase, continued to do so for several 
days. The necrotic lesions also increased in size during this period. By contrast with tomato aucuba mosaic virus in Nicotiana glutinosa, where the infectivity of extracts also decreased at first, infectivity did not increase until 2 days after inoculation; virus multiplication seemed to stop abruptly soon after the lesions appeared. These lesions increased in size subsequently, but only slowly. The apparently constant virus content of the leaves is most simply interpreted as indicating that virus has ceased multiplying, but it may be multiplying with multiplication being balanced by inactivation of virus in dead or dying cells or by the virus becoming less readily extracted from the dead tissue.

About 500 cells are involved in a necrotic lesion caused by tomato aucuba mosaic virus in a leaf of Nicotiana glutinosa. Virus seems to multiply in an epidermal cell and then to invade several hundred mesophyll cells, but these are killed and virus produced in them does not repeat the process of invading another large number of cells. When plants with necrotic local lesions are placed at $36^{\circ}$, a temperature at which tomato aucuba mosaic virus produces chlorotic and not necrotic lesions, the virus will invade neighbouring cells (Kassanis, 1952). What restricts the spread of virus in plants at lower temperatures is not known; death of the cells seems an inadequate explanation because when the temperature is raised to $36^{\circ}$ virus appears to move from dead to healthy cells.

In tobacco, as in Nicotiana glutinosa, when inoculated with tobacco mosaic or tomato aucuba mosaic viruses, the infectivity of successive leaf extracts decreases before it increases. With an inoculum containing $2000 \mathrm{mg}$. tobacco mosaic virus/l., the relative infectivity of extracts made after $3 \mathrm{hr}, 2,3$ and 4 days, was 229, 40, 302 and 865 respectively. Extracts made from tobacco leaves, 2 hr., 1, 2, 3 and 5 days after inoculation with $1000 \mathrm{mg}$. tomato aucuba mosaic virus/l. produced $22,6,7,13$ and 157 lesions respectively when inoculated at a dilution of $1 / 5$ to six half-leaves of tobacco. The times after inoculation when these viruses increased detectably are certainly not the minimum times, because in other experiments tobacco mosaic virus increased between 24 and $31 \mathrm{hr}$., and Yarwood (1952) detected an increase in $14 \mathrm{hr}$. at $24^{\circ}$.

\section{Inactivation of the inoculum}

As the three viruses and host plants used all gave qualitatively similar results, it seems to be usual rather than exceptional for the infectivity of extracts from inoculated leaves to decrease before increasing. The phenomenon was therefore studied in some detail with RTNV in tobacco and French bean, to gain information on the factors that affect it and to try to assess its cause and significance. Work with some bacterial viruses shows that they undergo considerable changes while infecting their host cells, and that for approximately half the time between infection and the lysing of the bacteria, these contain no particles that are infective or have the morphology of infective phages. By analogy, then, the loss of infectivity after plant viruses are inoculated to leaves might also reflect some change that virus particles undergo as a preliminary to multiplying in leaf cells. It is equally possible 
that virus particles in excess of those that infect and cause lesions may become inactivated on or in the leaf.

Experiments were first made to see how the decrease in infectivity is affected by treatments which increase or decrease the number of lesions produced by a given amount of virus rubbed over the leaves. Tobacco leaves were rubbed, half with infective sap alone and half with sap containing 'Celite'; half of the inoculated leaves in each lot were washed thoroughly 5 min. after inoculation. Newly formed virus was first detected in leaves that were rubbed with sap containing 'Celite', which greatly increases the number of lesions produced. Table 3 shows that 'Celite' did not affect the rate at which the infectivity of extracts decreased, or the proportion of the inoculum that was removed by washing. Washing, which decreases by about $20 \%$ the number of lesions produced, removed about $95 \%$ of the inoculum applied to the leaves. Clearly the inoculum can be considered in two parts. About $5 \%$ is in some way rapidly fixed to the leaf so that it is not removed by washing; this seems to be the only part that is concerned in causing lesions. The proportion of the part that does cause lesions depends on the method of inoculation and is much increased by 'Celite'; it also depends on the physiological state of the leaves, for although the same proportion of the inoculum is retained by washed leaves of various ages and in different physiological states, the numbers of lesions produced differs greatly.

\section{Table 3. The decrease in residual infectivity of an inoculum applied to tobacco leaves}

Virus : Rothamsted tobacco necrosis. Inoculum was infective French bean sap diluted 1/4. Total lesions produced on eight half-leaves of French bean by samples diluted $1 / 5$ and containing 'Celite' were counted.

\begin{tabular}{|c|c|c|c|c|}
\hline \multirow[b]{2}{*}{$\begin{array}{l}\text { Period between } \\
\text { inoculation and } \\
\text { sampling }\end{array}$} & \multicolumn{2}{|c|}{ Inoculum with 'Celite' } & \multicolumn{2}{|c|}{ Inoculum without 'Celite' } \\
\hline & Leaves washed & $\begin{array}{r}\text { Not washed } \\
\text { No. }\end{array}$ & $\begin{array}{l}\text { Leaves washed } \\
\text { esions }\end{array}$ & Not washed \\
\hline $3 \mathrm{~min}$. & 36 & 520 & 34 & 505 \\
\hline $1 \mathrm{hr}$. & 21 & 314 & 25 & 309 \\
\hline $5 \mathrm{hr}$. & 27 & 177 & $\mathbf{9}$ & 223 \\
\hline $24 \mathrm{hr}$. & 230 & 565 & 17 & 106 \\
\hline
\end{tabular}

The decrease in infectivity of successive extracts is proportionally the same with washed and unwashed leaves, although extracts from unwashed leaves are more infective. As most of the virus from unwashed leaves is not concerned in producing lesions, the simplest explanation for the phenomenon is that it reflects the loss of infectivity by excess of inoculum. It is unlikely to happen because virus particles become increasingly adsorbed by the leaf surface with the passing of time, for Table 4 shows that as much virus was removed from leaves when washed at $65 \mathrm{~min}$. as when washed $5 \mathrm{~min}$. after inoculation.

Even washed leaves retain far more virus particles than the number of lesions that develops. Indeed, from experiments with inocula containing 'Celite' 
and known weights of virus, in my experimental conditions about $10^{5}$ particles need to be applied to leaves to get a single lesion. Thus for every one that succeeds in producing a lesion, many fail, and it is the inactivation of the failures that probably causes the decrease in infectivity of successive extracts. Whether the inactivation of virus that cannot be washed from the leaves occurs because of some abortive first step towards multiplication is unknown, but there would seem to be no need to suspect this for the virus that can be removed by washing. For the inactivation of this, there is with RTNV no need even to suppose that the leaf is playing any active part, for much infectivity is also lost when inocula are simply dried in watch-glasses at room temperature and then resuspended in water.

\section{Table 4. The effect of washing tobacco leaves at intervals after inoculation on the residual infectivity of the inoculum}

Virus: Rothamsted tobacco necrosis. Inoculum was infective French bean sap diluted $1 / 4$ and containing 'Celite'. Total lesions produced on sixteen half-leaves of French bean by samples diluted $1 / 5$ and containing 'Celite' were counted.

$\begin{array}{crrr}\begin{array}{c}\text { Period between } \\ \text { inoculation and } \\ \text { sampling }\end{array} & \begin{array}{c}\text { Leaves not } \\ \text { washed }\end{array} & \begin{array}{c}\text { Washed 5 min. } \\ \text { after inoculation } \\ \text { No. lesions }\end{array} & \begin{array}{c}\text { Washed 65 min. } \\ \text { after inoculation }\end{array} \\ 3 \mathrm{~min} . & 2075 & 2235 & 1765 \\ 1 \mathrm{hr} . & 835 & 67 & 1310 \\ 5 \mathrm{hr} . & 96 & 15 & 15\end{array}$

Tobacco mosaic virus is less affected than RTNV by drying, but if its inactivation in inoculated leaves is a consequence of infection, then the event can occur in apparently immune plants. When French bean leaves were inoculated with tobacco mosaic virus and washed, no lesions developed and no virus increase was detected by infectivity assays on leaf extracts. The infectivity of successive extracts decreased, as with plants in which tobacco mosaic virus multiplies. In one experiment, samples taken $2,8,24$ and $48 \mathrm{hr}$. after inoculation produced $280,127,78$ and 33 lesions respectively when inoculated at a dilution of 1/10 on eight half-leaves of Nicotiana glutinosa.

To investigate the effect of light and temperature on the decrease in infectivity, leaves of three batches of plants were inoculated with infective sap diluted 1/25 and extracts of the leaves made 1 and $10 \mathrm{hr}$. after inoculation. Two batches of plants were kept in the glasshouse, one in daylight and the other in darkness at the same temperature: the third batch was kept in a cool darkroom which was at $14^{\circ}, 17^{\circ}$ and $17 \cdot 5^{\circ}$ in different experiments. Plants kept in the glasshouse for a day in the dark after inoculation produced a third fewer lesions than those kept in the darkroom for a day or in normal glasshouse conditions for the whole period. Darkening leaves after inoculation decreases lesion number (Bawden \& Roberts, 1948) and decreasing the temperature increases it (Harrison, 1956); the two effects seem to offset each other. Table 5 shows the results of the infectivity assays on the leaf extracts: in the glasshouse, infectivity decreased by $10 \mathrm{hr}$. to a fifth of the $1 \mathrm{hr}$. value, irrespective of 
whether the leaves were in light or dark, whereas in the cooler darkroom it only decreased by half. Temperature but not light is important in determining the rate of the decrease in infectivity.

Table 5. Effect of light and temperature on the decrease in residual infectivity of the inoculum

Virus: Rothamsted tobacco necrosis. Inoculum was infective French bean sap diluted 1/25. Total lesions produced on forty-eight half-leaves $\left(6\right.$ expts. $\left.{ }^{*}\right)$ of French bean by samples diluted $1 / 5$ or $1 / 25$ and containing 'Celite' were counted.

Host plant-French bean

$\overbrace{\text { dil. } 1 / 5 \text { dil. } 1 / 25}^{\text {Glasshouse, light }} \overbrace{\text { dil. } 1 / 5 \text { dil. } 1 / 25}^{\text {Glasshouse, dark }} \overbrace{\text { dil. } 1 / 5}^{\text {Darkroom }}$

Period between inoculation and sampling

$1 \mathrm{hr}$.

$10 \mathrm{hr}$.

$\%\left(\frac{10 \mathrm{hr} . \text { figure }}{1 \mathrm{hr} . \text { figure }}\right)$

No. lesions

$\begin{array}{rrrrrr}2534 & 787 & 2330 & 711 & 3833 & 1190 \\ 468 & 139 & 584 & 149 & 2314 & 562 \\ 18.5 & 17 \cdot 7 & 25 \cdot 1 & 20 \cdot 9 & 60 \cdot 3 & 47 \cdot 2 \\ & & & & & \\ 18 \cdot 1 & \text { average } & 23 \cdot 0 \text { average } & & 53.8 \text { average }\end{array}$

* Temperatures in the six experiments: $A$ and $B$-glasshouse $23-27 \cdot 5^{\circ} \mathrm{C}$, average 26 ; darkroom 14 (constant): $C$ and $D$-glasshouse 20.5-25.5, average 24; darkroom 17.5: $\mathrm{E}$ and $\mathrm{F}$-glasshouse 17-24.5, average 21.5; darkroom 17 .

\section{The rate of virus increase}

The rate of increase of RTNV in French bean leaves was investigated by sampling the leaves at frequent intervals after inoculation. The results of one such experiment, in which the leaf samples taken contained about 430 lesions or lesion sites and gave extracts of $1 \mathrm{ml}$. in volume, are shown in Table 6; successive tenfold increases in the infectivity of leaf extracts as measured at $19 \mathrm{hr}$. after inoculation, occurred in $3,7 \cdot 5,10$ and $19 \mathrm{hr}$. periods, and a further fivefold increase took 30.5 hr. more. The sample taken $89 \mathrm{hr}$. after inoculation produced 180 lesions on eight half-leaves of test plants at a dilution of $1 / 15,625$, using 'Celite': $0.7 \mathrm{ml}$. was used in the inoculation. Assuming that $10^{5}$ particles are applied for every local lesion produced when 'Celite' is used, the number of virus particles in the $89 \mathrm{hr}$. sample was $\frac{1 \cdot 0}{0 \cdot 7} \times 15,625 \times 180 \times 10^{5}$. If then it be assumed that 1000 cells were infected at each of the 430 lesions at $89 \mathrm{hr}$., the average number of virus particles obtained from each cell can be calculated: $\frac{1 \cdot 0}{0 \cdot 7} \times 15,625 \times \frac{10^{5} \times 180}{430 \times 1000}=c .10^{6}$ particles. It is worth comment that this estimate, for a virus in host cells which it kills, is of the same order as estimates for tobacco mosaic virus in tobacco leaf cells (Harrison, 1955; Nixon, 1956), that is, in cells which continue to live and seem not to be seriously crippled by this quantity of anomalous particles. 
Table 6. Increase of tobacco necrosis virus in French bean leaves

Inoculum was infective French bean sap diluted 1/15. Total lesions produced on eight half-leaves of French bean were counted.

\begin{tabular}{|c|c|c|c|c|c|c|c|}
\hline \multirow{2}{*}{$\begin{array}{c}\text { Time between } \\
\text { inoculation } \\
\text { and sampling } \\
(\mathrm{hr} .)\end{array}$} & \multicolumn{6}{|c|}{ Dilution of sample ('Celite' added) } & \multirow{2}{*}{$\begin{array}{c}\text { Relative } \\
\text { virus } \\
\text { content* }\end{array}$} \\
\hline & $1 / 5$ & $1 / 25$ & $1 / 125$ & $1 / 625$ & $1 / 3125$ & $1 / 15,625$ & \\
\hline 1 & $2+1$ & - & - & - & - & - & 1.5 \\
\hline 17 & $6+5$ & - & - & - & - & 一 & $5 \cdot 5$ \\
\hline 19 & $5+14$ & - & - & - & - & - & $9 \cdot 5$ \\
\hline 22 & 102 & 30 & - & 一 & 一 & - & 118 \\
\hline 25 & 569 & 118 & - & - & - & - & 550 \\
\hline 28 & - & 172 & 25 & - & - & - & 715 \\
\hline 41 & - & - & 563 & 122 & - & - & 13,900 \\
\hline 45 & - & - & 772 & 215 & - & - & 21,750 \\
\hline 49 & - & - & - & 213 & 41 & - & 25,250 \\
\hline 65 & - & - & - & 1474 & 524 & - & 284,100 \\
\hline 89 & - & - & - & - & 895 & 180 & 501,900 \\
\hline
\end{tabular}

* $\frac{a+4.5 b}{2} \times \frac{D}{5} ; a=$ lesion count at lower dilution; $b=$ lesion count at greater dilution; $D=$ reciprocal dilution of ' $a$ '.

\section{DISCUSSION}

The results described in this paper show that when RTNV is multiplying in the epidermal cells of French bean leaves and invading the mesophyll (Bawden \& Harrison, 1955) the infectivity of leaf extracts not only does not increase from the time of inoculation but at first actually decreases. Only when newly produced virus starts to accumulate in the mesophyll cells, does there seem to be enough to detect by infectivity assays. Also, the presence of the first newly produced virus is masked by that of the residual inoculum. Some at least of the inoculum virus retained on leaves washed after inoculation seems to be inside wounded cells; Yarwood (1952) found that washing removed 99.9\% of tobacco mosaic virus sprayed on to leaves but only $94 \%$ of that inoculated by rubbing. The residual virus may lose its infectivity and this probably causes the decrease in infectivity of extracts of washed leaves with increasing times after inoculation. Or, instead of virus particles losing infectivity, the number of particles recovered in extracts of the leaves may have decreased. The experiments described above gave no evidence of this and Steere (1952), who counted the numbers of tobacco mosaic virus particles in extracts of tobacco leaves using an electron microscope, found that the numbers remained constant before multiplication was detected. There is no unequivocal evidence that the decrease in infectivity is irrelevant to the process of virus multiplication. It may, however, be caused by virus drying on the leaf and becoming non-infective, or conditions in wounded epidermal cells may favour virus inactivation, possibly of the kind which occurs when French bean leaves infected with RTNV are kept at $30^{\circ}$ (Harrison, 1956).

Some of the virus particles in preparations of potato virus $X$ that have been partially inactivated by ultraviolet radiation, multiply when the tobacco test 
plants are exposed to daylight after inoculation but not when the plants are kept in darkness (Bawden \& Kleczkowski, 1955). Most of the particles reach the light-sensitive state in $\mathbf{3 0} \mathrm{min}$. after inoculation and they remain in this state for only $1 \mathrm{hr}$. more. This suggests that only those particles of potato virus $X$ that undergo a change within $1.5 \mathrm{hr}$. after inoculation multiply and cause lesions. It is dangerous to argue from results obtained with potato virus $X$ in tobacco to RTNV in French bean, but the results strongly suggest that changes which occur later than 2-3 hr. after inoculation do not reflect the initial stages of a process that ends in virus multiplication. The fact that RTNV from the inoculum continues to lose infectivity at least until new virus has probably started to accumulate in secondarily infected cells, when ultraviolet irradiation of the leaves prevents few or none of the lesions developing, suggests therefore that most of the decrease in infectivity is separate from the processes which lead to production of new virus.

By analogy with bacteriophage multiplication, it might be expected that soon after infection the virus content of leaves would increase in 'steps', the virus represented by each 'step' coming from a different set of sites of multiplication. This does not happen with RTNV in French bean leaves, probably because the leaf cells continue to produce RTNV for a period several times longer than that needed for production to start. By contrast, the secondarily infected cells of Nicotiana glutinosa leaves seem to continue producing tobacco mosaic or tomato aucuba mosaic viruses for only a fraction of the period needed for the first to form, and there is the appearance of a single 'step'. Only one 'step' occurs because the virus formed in the epidermal cells infected at inoculation is not detected, and virus seems to spread to few of the cells which surround the secondarily infected ones; Fig. 1 thus represents the accumulation of virus in secondarily infected cells. Results obtained with tobacco mosaic virus in Datura stramonium leaves (White, 1954) can be interpreted similarly.

This work was done during the tenure of an Agricultural Research Council research studentship.

\section{REFERENCES}

Bawden, F. C. \& Harrison, B. D. (1955). Studies on the multiplication of a tobacco necrosis virus in inoculated leaves of French-bean plants. J. gen. Microbiol. 13, 494.

BAwden, F. C. \& KLECzKowski, A. (1955). Studies on the ability of light to counteract the inactivating action of ultraviolet radiation on plant viruses. J. gen. Microbiol. 13, 370.

Bawden, F. C. \& Pirie, N. W. (1953). Virus multiplication considered as a form of protein synthesis. In The Nature of Virus Multiplication. Cambridge University Press.

Bawden, F. C. \& Roberts, F. M. (1948). Photosynthesis and predisposition of plants to infection with certain viruses. Ann. appl. Biol. 35, 418.

Harrison, B. D. (1955). Studies on the multiplication of plant viruses in inoculated leaves. Ph.D. Thesis, University of London.

Harrison, B. D. (1956). Studies on the effect of temperature on virus multiplication in inoculated leaves. Ann. appl. Biol. 44, 215. 
Holmes, F. O. (1930). Local and systemic increase of tobacco mosaic virus. Amer. J. Bot. 17, 789.

Kassanis, B. (1952). Some effects of high temperature on the susceptibility of plants to infection with viruses. Ann. appl. Biol. 39, 358.

Nrxon, H. L. (1956). A direct estimate of the number of tobacco mosaic virus particles in a hair cell. Virology, 2, 126.

Steere, R. L. (1952). Virus increment curves obtained from counts of particles in clarified plant juice. Amer. J. Bot. 39, 211.

White, N. H. (1954). Infectivity of tobacco mosaic virus after inoculation on 'Datura stramonium'. Aust. J. Sci. 17, 50.

YARwOoD, C. E. (1952). Latent period and generation time for two plant viruses. Amer. J. Bot. 39, 613.

(Received 26 February 1956) 